3. Фиксман Б. A. Светорассеяние взвесей бактерий в видимой области спектра // Бнофизика.- 1963.-8, № 3.- С. $380-384$

4. Евдокимов Ю. М., Скуридин С. I., Акименко Н. М. Жидкокристаллические микрофазы низкомолекулярных двухцепочечных нуклеиновых кислот и синтетических по.тннукеотидов // Высокомолеку.яя. соединения.-1984.- А26, № 11.— С. 2403-2410.

5 Protein measurements with Folin phenol reagent/O. H. Lowry, N. J. Rosebrouh, 1. L. Farr, R. J. Randall // J. Biol. Chem-1951-193, N 1. P. 265-275.

6. Сомин Н. Я. Определение размера частиц по светорассеянию//Оптика и спектро

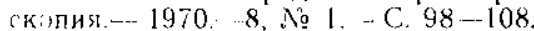

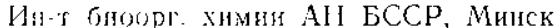

Іолучено 10.03 .89

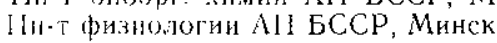

Белорус. гос. ун-т им. В. И. Ленина, Минск

Ин-т фотобногогин АН БССР, Минск

\title{
STUDIES OF DNA INTERACTION WITH PROTEIN CONTAMINANTS
}

A. A. Akhrem, V. P. Egorova, A. S. Egorov, V. I. Krol, D. Yu. Lanto, Z. A. Luka

Institute of Bioorganic Chemistry,

Academy of Sciences of the Byelorussian SSR, Minsk

Institute of Physiology,

Academy of Sciences of the Byelorussian SSR, Minsk

Lenin Byelorussian State University, Minsk

Institute of Photobiology,

Academy of Sciences of the Byelorussian SSR, Minsk

St m m a t y

DVA isolated from the bovine spleen has been investigated for its interaction witl protein contaminants. It is shown that the contaminants are not histones and their binding is determined by the nonionic contacts which are destroyed in the presence of urea and relain with high concentrations of $\mathrm{XaCl}$. The protein contaminants do not change thermustability of DNA and they are distributed irregularly among the macromolecules: less than $10 \%$ of DNA contains more than $70 \%$ of all the proteins.

УДК 577.323 .425

В. А. Сорокин, В. Л. Галкин, В. А. Валеев, Е. С. Архипова, Г. О. Гладченко, Ю. П. Благой

ИЗУЧЕНИЕ ЭНЕРГЕТИКИ ГИЦРАТАЦИИ КОМПОНЕНТОВ НУКЛЕИНОВЫХ КИСЛОТ
МЕТОДОМ ЦИФФЕРЕНЦИАЛЬНОЙ УФ-СПЕКТРОСКОПИИ *

Дая определения териодннамических параметров гидратачии оснований киклеотидов измерены темисратурнье зависимости дифференциальньх УФ-спектров поглоцения

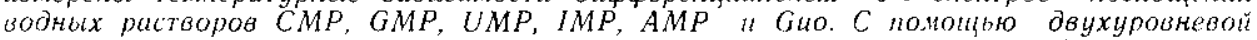

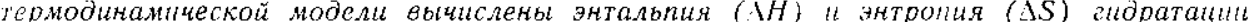
молекул водь. образуюцих внутренний моногидратный слой вблизи оснований. Д.яя UMP, IMP, GMP и Gио гидратация приводит к возрастанию энтропиа, которое вносит

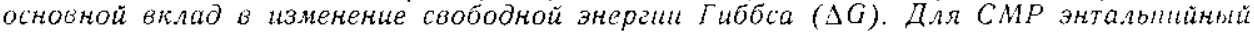
"з энтропийный члень сравнимь по величине, чем объясняется аномально низкое знаненuе $\mid \triangle G !$. Обнаружена корреляиия между величиной $\Delta H$ и знатеними дипольного монента основного состояния. Гидратация приводит $к$ возрастанию энереии злектроннех переходов оснований.

Введение. Для выяснения элергетики специфических взаимодействий ДНК с низкомолекуляріыми лигандами в водных растворах необходнма ипформация о термодипамических параметрах, характеризующих ги,цатацию гетероатомов оснований пуклеотндов.

Хотя калориметрия является прямым и наиболее точным методом определения теплот гидратации, она не позволяет разделить вклады,

* Представлена членом редколлегии Н. В. Желтовским. 
обусловлснные гидратацией отдельных групп: фосфатов, рибозы и оснований, энергетика связывания которых с молекулами воды существенно отличается [1]. Попытка такого разделения [1] была сделана на основании приложения теории сорбции газовой фазы гетерогенными сорбелтами к описанию экспериментальных изотерм гидратации, получснных методами ИК-спектроскопии и СВЧ-диэлектрометрии. Однако интерпретация теоретических представлений в этом случае достаточно сложна [1]. В связи с этим особый иптерес для изучения взаимодействия мономеров нуклеиновых кислот с молекулами растворителя представляет метод тсмпературно-зависимой дифференциальной УФспектроскопии [2-4]. УФ-спектроскопия малочувствительна к взаимодействию лигандов (в том числе и молекул воды) с фосфатными группами и рибозой [5]. Наблюдаемые при ее использовапии изменения спектров поглощения нуклеотидов должны практически полностью определяться гидратацией основапий в координационном («моногидратном» [6]) слое. Это обстоятельство является главным преимуществом метода диффсренциальной УФ-спектроскопии по сравнению с другими спектроскопическими методами $[1,6-8]$.

Цель настоящей работы состояла в том, чтобы показать возможности метода дифференциальной УФ-спектроскопии в определении энтальпии и эІтропии гидратации оспований нуклеотидов.

Материалы и методы. Объектом исследования служили динатриевые соли рибонуклеозид-5'-фосфатов: цитидина (CMP), гуанозина (GMP) («Serva», ФPГ), уридина (UMP), инозина (IMP), аденознна (AMP) («Reanal», BHP), а также гуанозин (Guo) («Chemapol», Чехословакия). Все препараты растворяли в деионизованном дистилляте, в который добавляли $\mathrm{NaOH}$ (для достижения $\mathrm{pH} 7,0$ ) и $\mathrm{NaCl}$. Общая концентрация ионов $\mathrm{Na}^{+}$в растворе составляла $10^{-3} \mathrm{M}$. Концентрацию нуклеотидов и гуанозина $(B)$, равную $(7,2 \div 10) \cdot 10^{-5} \mathrm{M}$, определяли по величине коэффнциента молярной экстинкции в максимуме спектра поглощения (табл. 1).

Т а б ли и а 1

Положение максимумов $\left(v_{\max } \cdot 10^{-3}, \mathrm{CM}^{-1}\right)$ и соответствующие им козффиұиенты молярной экстинкции $\left(\varepsilon_{\max } \cdot 10^{-2}, \mathrm{M}^{-1} \mathrm{CM}^{-1}\right)$ для наиболее интенсивных полос в спектре УФ-поглощения водных растворов нуклеотидов,

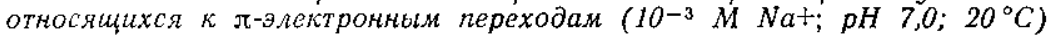

Maxima positions $\left(v_{\max } \cdot 10^{-3}, \mathrm{~cm}^{-1}\right)$ and corresponding molar extinction coefficients $\left(\varepsilon_{\max } \cdot 10^{-2}, \mathrm{M}^{-1} \mathrm{~cm}^{-1}\right)$ for the most intensive bands in $U V$ absorption spectra of nucleotide aqueous solutions, assigned to $\pi$-electron transitions $\left(10^{-3} \mathrm{M} \mathrm{Nat}, \mathrm{pH} 7.0,20^{\circ} \mathrm{C}\right)$

\begin{tabular}{l|c|c|c|c}
\hline \multirow{2}{*}{ Нуклеопид } & \multicolumn{2}{|c|}{$I\left(\pi \rightarrow \pi^{*}\right)$} & \multicolumn{2}{|c}{ II $\left(\pi \rightarrow \pi^{*}\right)$} \\
\cline { 2 - 5 } & $v_{\max }$ & $\varepsilon_{\max }$ & $v_{\max }$ & $\boldsymbol{\varepsilon}_{\max }$ \\
\hline & & & & \\
CMP & $36,7 \pm 0,2$ & $91[9]$ & $43,6 \pm 0,5 * *$ & 81 \\
UMP & $38,1 \pm 0,2$ & $100[9]$ & $49 \pm 0,2$ & 100 \\
AMP & $38,3 \pm 0,3$ & $153[9]$ & $48,3 \pm 0,2$ & 213 \\
IMP & $40,1 \pm 0,2$ & $123[9]$ & $49,4 \pm 0,2$ & 150 \\
GMP, Guo & $37 \pm 0,6^{* *}$ & 97,7 & $39,5 \pm 0,2$ & $137[9]$ \\
\hline
\end{tabular}

П р м ечание. Максимальная ошибка определения величины $\varepsilon$ составлияет $\pm 1 \%$.

** Регистрируется на спектре в виде плеча.

Дифференцильные ультрафиолетовые спектры (ДУФС), индуцированные нагреванием $\left(\Delta A_{h}\right)$, измеряли на спектрофотометре «Specord UVVIS» фирмы «Carl Zeiss Iena» (ГДР) по двухкюветной схеме: кюветы с идентичными растворами нуклеотидов помеща.ли в оба канала спектрофотометра. В эталонной кювете поддерживали температуру $20^{\circ} \mathrm{C}$, в рабочей - повышали ступенчатым нагревом со скоростью $0,3 \pm 0,1$ град/мин с шагом $10^{\circ} \mathrm{C}$. Растворы выдерживали в течение 20 мин при каждой температуре для установления теллового равновесия между кюветой и термостатирующим блоком. Точность термостатирования кювет при всех температурах составляла $\pm 0,02^{\circ} \mathrm{C}$. Градиент 
в кюветах не превышал $0,1^{\circ} \mathrm{C}$ [10]. В экспериментальные спектры $\triangle A_{h}$ вводили поправку на тепловое расширение раствора в рабочей кювете, используя данные о температурной зависимости коэффициента теплового расширения воды [11]. Дифференциальные спектры нормировали на концентрацию нуклеотидов: $\Delta \varepsilon_{h}=\Delta A_{h} / B$.

Результаты и обсуждение. При нагревании нуклеотидов их спектр поглощения изменяется (рисунок). В случае CMP, AMP, IMP и UMP происходит красный сдвиг основной полосы поглощения (полоса I, табл. 1), приводящий $\mathrm{K}$ появлению самых длинноволновых экстремумов на ДУФС (рисупок). В случае GMP (рисунок, полосы (полоса II, табл. 1) индуцирует появленне промежуточных экстремумов, расположенных при $v_{\max }=38000$ и $v_{\min }=41700 \mathrm{~cm}^{-1}$, тогда как самые длинноволновые - обусловлены красным смещением менее интенсивной полосы I (табл. 1). Для СМР два экстремума в области $v=(40-44) \cdot 10^{3} \mathrm{~cm}^{-1}$ индуцированы батохромным сдвигом полосы II (табл. 1). Наконец, самые коротковолновые максимумы на ДУФС АМР и UMP и возрастание поглоцения в этой области волиовых чисел для остальных нуклеотидов обусловлены красным сдвигом нитенсивных по-

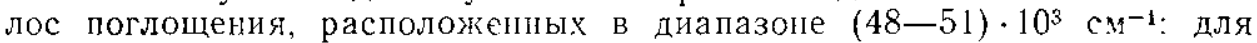
UMP, AMP и IMP - полось́ II (табл. 1), для CMP. GMP и Guо полось́, расположенной при $v_{\max }=(50,6 \pm 0,2) \cdot 10^{3} \mathrm{~cm}^{-1}$ (при одинаковом значении $v_{\max }$ для CMP $\varepsilon_{\max }=22800 \mathrm{M}^{-1} \mathrm{~cm}^{-1}$; для GMP и Guо $\varepsilon_{\max }=$ $\left.=2 \mathrm{i} 100 \mathrm{M}^{-1} \mathrm{~cm}^{-1}\right)$. Появление плечей на спектрах $\Delta \varepsilon_{h}$ в случае IMP $\left(v_{\max } \sim 35000 \mathrm{~cm}^{-1}\right)$ н AMP $\left(v_{\max } \sim 42500 \mathrm{~cm}^{-1}\right)$ (рисунок, в, 2) является результатом сдвига не регистрируемых на УФ-спектрах малоинтенсивных полос поглощения, расположенных соответственно при $\nu_{\max }=(37,4 \pm 1) \cdot 10^{3}$ и $(42-43) \cdot 10^{3} \mathrm{~cm}^{-1}[12]$.

При нагревании раствора гуанозина спектральные изменения подобны наблюдаемым в случае GMP. Отличие заключается в том. что самые длинноволновые экстремумы на спектрах $\Delta \varepsilon_{h}$ гуанозина смешены по сравнению с ДУФС GMP в красную сторону на 500 см ؛. Эго обстоятельство, как и несколько бо́льшая интенсивность промежуточных экстремумов, свидетельствует о большем сдвиге полос I I II в случае пуклеозида. В целом же форма и ннтенсивность всех измеренных дифференциальных спектров согласуются с данными, полученными для оснований, нуклеозидов и нуклеотидов в других ионных условиях $[2,4]$.

Возможными причинами изменения спектров поглощения мономеров в растворах при нагреванин, в принцие, могут быть измененис равновесия ассоциация - диссоциация, таутомерные переходы, уменьшение констант ионизации гетероатомов основанй $\left(p K_{a}\right)$ н, наконец, измененис изаимодействия с молскулами растворитсля. Аиализ этих причии, выполненный в работе [2], показал, что в разбавленных $(B<$ $<10^{-2} M$ [13]) водных растворах при нейтралыных значениях $\mathrm{pH}$ влияиие ассоциации, таутомеризации и уменьшения $p K_{a}$ несущественио, н основной вклад в изменение спектров поглощения вносит дегидратация. Этот вывод был подтвержден при анализе формы дифференциальных спектров, индуцируемых измененисм состава растворителя [2].

Поскольу паблюдаемые на рисунке спекралиыс изменения обус ловлены дегндратацией $[2,4]$, можно сделать вывод о том, что гидратация нуклеотндов и гуанозниа приводит к kоротковолновому саны. гу всех (как интенсивиых, так и малоннтенсивных) полос поглошения. Это озпачаст увеличение энергін всех синтет!ых электроних исреходов, что соотвстствует уменьпению дипольных моментов возо́хжденного состояния оснований.

Полученные температурные зависимости ДУФС (рисунок) позволяют рассчитать энтальпию $(\Delta H)$ и энтропию $(\Delta S)$ гидратации но формуле (1), полученной в модели двух состояний (одно состояние соответствует полностью гидратированному основанию, другое -- потностью 

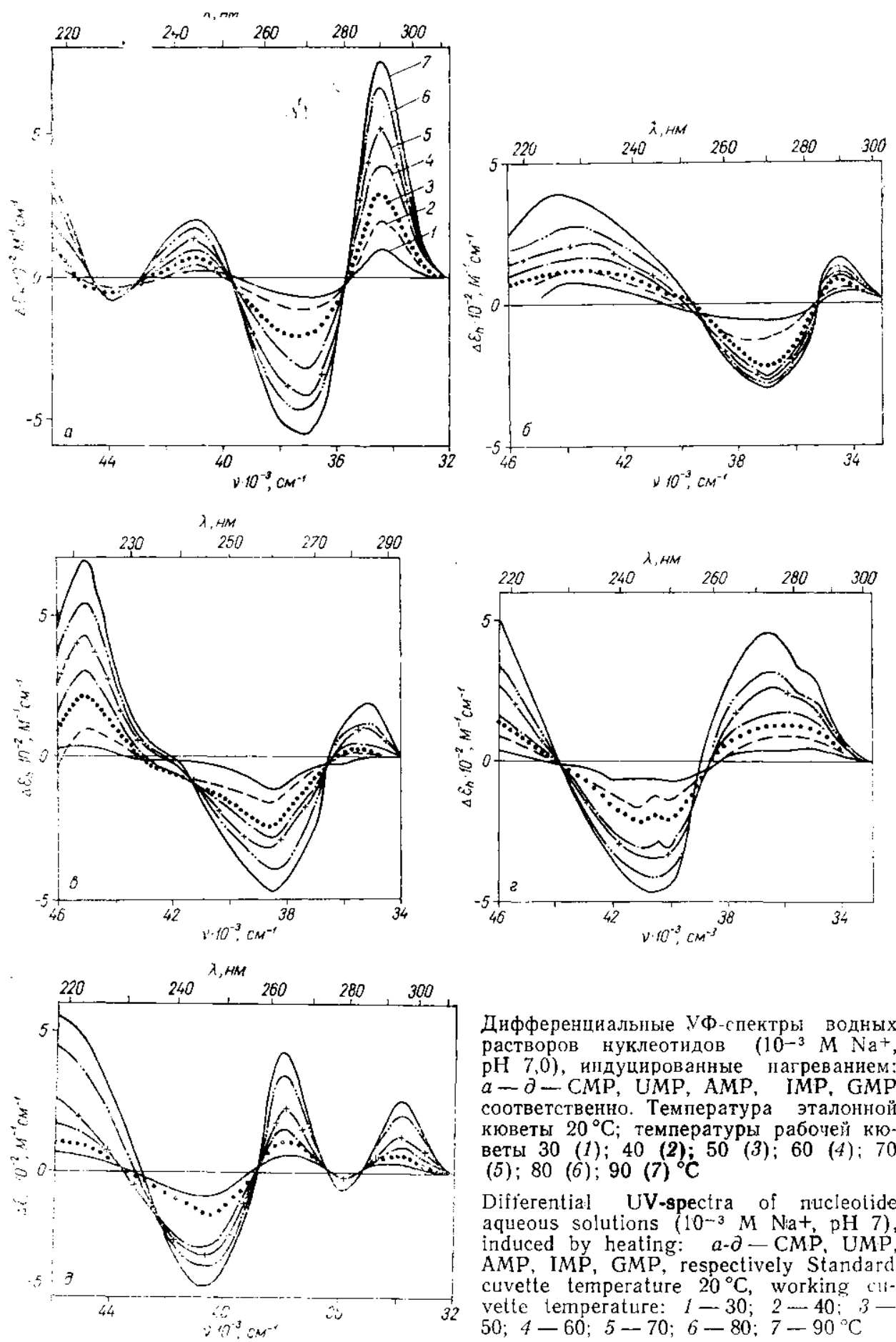

Дифференциальные УФ-спектры водных растворов нуклеотидов $\left(10^{-3} \mathrm{M} \mathrm{Na}^{+}\right.$, $\mathrm{pH} 7,0$ ), нндуцированные нагреванием: $a-\partial-C M P$, UMP, AMP, IMP, GMP соответственно. Температура эталонной кюветы $20^{\circ} \mathrm{C}$; температуры рабочей кюветы 30 (1); 40 (2); 50 (3); 60 (4); 70 $(5) ; 80(6) ; 90(7)^{\circ} \mathrm{C}$

Differential UV-spectra of nucleotide aqueous solutions $\left(10^{-3} \mathrm{M} \mathrm{Na}+\mathrm{pH} 7\right)$, induced by heating: $a-\partial-C M P$, UMP AMP, IMP, GMP, respectively Standard cuvette temperature $20^{\circ} \mathrm{C}$, working c!ivetie temperature: $1-30 ; 2-40 ; 3-$ $50 ; 4-60 ; 5-70 ; 6-80 ; 7-90^{\circ} \mathrm{C}$

дегидратированному) [3] .

$$
\begin{gathered}
\left.\left(\Delta \varepsilon_{h_{p}}\right)_{T, v}=\left(\Delta \varepsilon_{h}\right)_{T_{1}, v}+\left[\left(\Delta \varepsilon_{h}\right)_{T_{2}, v}-\left(\Delta \varepsilon_{h}\right)_{T_{1}, v}\right]_{2}^{*}(1)+\gamma b_{T_{2}, v}\right) \times \\
\times\left(b_{T_{1}, v}-b_{T, v}\right) /\left(1+\gamma b_{T, v}^{*}\right)\left(b_{T_{1}, v}-b_{T_{2}, v}\right) ; \\
\gamma=e^{\Delta S / R} ; \quad b_{T, v}=\left(e^{-\Delta H / R T}\right)_{v} ; \quad b_{T_{i}, v}=\left(e^{-\Delta H / R T_{i}}\right)_{v} ; \quad i=1 ; 2 .
\end{gathered}
$$

Здесь $\Delta \varepsilon_{h}$ и $\Delta \varepsilon_{h p}{ }^{\circ}$ - соответственно экспериментальные и расчетные значе- 
ния интенсивности ДУФС при различных волновых числах (v) и темпера$\operatorname{typax}(T) . T_{1}=313 \mathrm{~K}, T_{2}=353 \mathrm{~K}$ - температуры, при которых полагали, что $\Delta \varepsilon_{h_{p}}=\Delta \varepsilon_{h}$.

Выражение (1) основано на предположении о лиюейюм вкладе в спектры поглощения гидратированных и дегидратированных оснований, относительное количество которых при зацапиой температуре определяется термодинамическим равновесием в двухуровневой системе. Такая модель тем точнее, чем меньше молекул воды опрсделяет изменение спектров поглощения, поскольку число промежуточных состояний при этом должно также уменьшаться. Согласно экспериментальным данным [1,7, 8] и теоретическим расчетам [14], число молекул воды $(n)$, связанных атомами кольца оспований, действительно невелико: в зависимости от их природы $n=2 \div 5$ (табл. 2).

Т а б гі и а 2

Термодинамические параметры аидратации оснований нуклеотидов, полуиенные методом дифференциальной УФ-спектроскопии, в рамках двухуровневоі

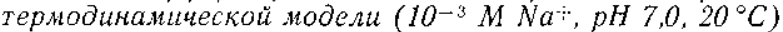

Thermodynamic parameters for hydration of nucleotide bases, obtained by DUVS in the frame of the two-leveled thermodynamic model $\left(10^{-3} \mathrm{M} \mathrm{Na} ;\right.$ pH $\left.7.0 ; 20^{\circ} \mathrm{C}\right)$

\begin{tabular}{|c|c|c|c|c|c|c|}
\hline Параметры & LMP & AMP & IMP & GMP & Guo & CMP \\
\hline $\begin{array}{l}\Delta H, \text { ккал/моль } \\
T \Delta \mathrm{S}, \text { ккал/ моль } \\
\Delta G, \text { ккал/моль } \\
\mu, D[15] \\
n \\
\Lambda H / n, \text { ккал/моль }\end{array}$ & $\begin{array}{r}-2,5 \\
14,9 \\
-17,4 \\
4,6 \\
1[1] \\
-2,5\end{array}$ & $\begin{array}{c}-3,4 \\
14,2 \\
-17,6 \\
2,9 \\
4 \div 5[7] \\
-(0,9 \div 0,7)\end{array}$ & $\begin{array}{r}-3,8 \\
14,2 \\
-18,0 \\
\cdots \\
-- \\
-\end{array}$ & $\begin{array}{r}-6,2 \\
11,9 \\
-18,1 \\
7,5 \\
4[1] \\
\cdots 1,6\end{array}$ & $\begin{array}{l}-6,0 \\
13,2 \\
-19,2 \\
-7,5 \\
-\end{array}$ & $\begin{array}{c}-6,3 \\
-4,8 \\
-1,5 \\
7,6 \\
2 \div 3[1,8] \\
-(3,2 \div 2,1)\end{array}$ \\
\hline
\end{tabular}

Величины $\Delta H$ и $\Delta S$ определяли минимизацией квадратичного отклонения $(\chi)$ модифицированным методом Пауэлла [16]:

$$
\chi^{2}=\sum_{T, v}\left[\left(\Delta \varepsilon_{h_{p}}\right)_{T, v}-\left(\Delta \varepsilon_{h}\right)_{T, v}\right]^{2} .
$$

Точность вычисления минимума опрсделястся по изменению двухмсрного вектора $\vec{x}(\Delta H, \Delta S)$. Вычисление заканчивалось, если

$$
\text { NORMA }[\vec{x}(k+1)-\vec{x}(k)\}<a \cdot \operatorname{NORMA} \overrightarrow{[x}(k)+E]
$$

где $k$ - номер итерации, $E=10^{-12}$ - точность, задаваемая в процессе зычислепия, $a=2^{-21}[17]$.

Расчеты проведспы на ЭВМ ЕС-1045 в диалоговом режиме с использованием диалоговой системы ДИСО [17]. Для уменьшения влияния случайґых эксперимептальных ошибок минимизацию проводили по несколькнм (трем-пяти) волновым числам. При этом наибольшие отклонения значений $\Delta H$ и $\Delta S$, приведенных в табл. 2, от полугенных при минимизации по отдельным волновым числам и их различпым комбинациям (они определяют максимальгую экспериментальную опибку) составили \pm 10 н $\pm 12,5 \%$ для $\Delta H$ и $\Delta S$ соответственно.

Қак видно из табл. 2, энтальпия гидратащии оснований CMP, GMP и Guо одинакова и в $1,6 \div 2,5$ раза больше, чем для остальных нуклеотидов. Поскольку возмущающее спектр поглощения взаимодействие молекул воды с кольцами оснований определяется главным образом диполь-дипольиым взаимодействием [18], то причина этих различий $\Delta H$ должна опредсляться соответствующим отличием величин дипольного момента основапий. Действительно, наблюдается удовлетворительная корреляция между изменением эксперименталыных значений $\Delta H$ и рассчитанных тсоретически всличин суммарного дипольного момснта основного состояния оснований $(\mu)$ : значения $\mu$ для гуанина и цитозина также одипаковы и соответственно в $1,6 \div 2,6$ раза больше, чем для 
аденина и урацила (табл. 2). Этот результат показывает, что найденные величины $\Delta H$ характеризуют взаимодействие только тех молекул воды, которые находятся в непосредственной близости к гетероатомам основапий. Другие молекулы гидратной оболочки, связанные с фосфатами и рибозой, а также находящиеся в ее внешних слоях, практически не способны влиять II электронные переходы нуклеотидов. Равенство значений $\Delta H$ для GMP и Guо подтверждает этот вывод. Нормирование полученных величин $\Delta H$ на число молекул, гидратирующих основания пуклеотидов $(n)$, пает удельные значения $\Delta H / n$ $(0,7 \div 3,2$ ккал/моль, табл. 2), близкие к величицам, характеризуюпим гидратный слой ДНК $(1,2 \div 2,3$ ккал/моль) [6]. Хотя эти молекулы воды связаны с основаниями нуклсотидов наиболее сильго $[6,19]$, абсолютные значения $\Delta H$ невелики и сравнимы с величиной энтальпии связывапия ионов переходных металлов. Так, например, для комплекса ионов $\mathrm{Cu}^{2+}$ с N3 поли (C) $\Delta H=-3,5$ ккал/моль [20], а с N7 метилпу. рина $-\Delta H=-4,5$ ккал/моль [21]. Таким образом, в водных раствоpax ионы металлов и молекул воды являются конкурентами за связывание активных цептров на основаниях нуклеиповых кислот. Меньшая величина модуля энтальпии гидратации, возможно, является причиной, по которой при образовании комплексов иопы переходных металиов связываются с гетероатомами колец непосредственно [13].

Для большинства изученных веществ гидратация увеличивает энтропию нуклеотида $(\Delta S>0)$, причем энтропийный член впосит основной вклад в изменение свободной энергии Гиббса $(\Delta G=\Delta H-T \Delta S)$, которое для UMP, AMP, IMP, GMP и Guо практически одинаково (табл. 2).

Неожиданными оказались энтропийные характеристики СMP, Для которого $\Delta S<0$. Последнее, как и близость модулей энтальпийного и энтропийного членов, приводит к аномально малой для этого нуклеотида абсолютной величине $\Delta G$ (табл. 2).

Цитидин характеризуется самой большой величиной константы ионизации гетероатомов оснований $\left(p K_{a}=4,22\right.$ [2]), поэтому можно было предположить, что причиной этой особенности является частичная его ионизация при повышении температуры. Однако максимальное отличие температурных зависимостей $\Delta \varepsilon_{h}$, полученных при использовании фосфатного буфера $(\mathrm{pH} 7,0)$, от приведенных на рисунке, $a$ составило $\pm 10 \mathrm{M}^{-1} \mathrm{~cm}^{-1}$, что находится в пределах ошибки измерения изменения поглощения спектрофотометром $\left( \pm 25 \mathrm{M}^{-1} \mathrm{~cm}^{-1}\right)$. Таким образом, причина аномального знака энтропийного члена для CMP не ясна. Тем не менее можно отметить, что среди всех оснований цитозин обладает самым низким значением дипольного момента синглетного возбужденного состояния. Его величина $\left(\mu^{*}=0,884 D\right)$ в $2 \div 5$ раз меньше, чем для других канонических оснований [22]. Поскольку время нахождения оснований в возбужденном состоянии $\left(10^{-12}-10^{-13} \mathrm{c}\right.$ [23]) сравнимо с таковым для молекулярных колебаний и перестроек в гидратной оболочке $\left(10^{-13}-10^{-12}\right.$ с [24]), то возбужденное состояние также может, в принципе, влиять на параметры гидратации основаиий. Этим, возможно, объясняется аномалия поведения эгтропии СМР.

С другой стороны, имеет место корреляция полученных нами данных с результатами недавно опубликованной работы Букина [25], который обпаружил, что модуль молярной адиабатической сжимаемости $\left(\beta_{s}\right)$ гидратной оболочки цитозина в $1,5 \div 4,5$ раза больше, чем у других канонических осповапий. Поскольку величина $\beta_{s}$ опредслястся структурпым состоянием связанных молекул воды [25], то ее анома.тия должпа коррелировать с поведением именно эाтропийного тлена свободной энергии гидратации.

Таким образом, применение метода дифферсициальной УФ-спектроскопии позволило определить тсрмодинамические параметры гидратации компопентов пуклеиновых кислот, характеризуюшие гидратпыи слой, паходящийся в пепосредственной близости от гетероатомов оснований. 
В заключение авторы выражалот благодарғость $M$. А. Семенову и А. Б. Теплицкому за обсуждение результатов работы и полезные замечания.

\section{СПИСОК ЛИТЕРАТУРЫ}

1. Стариков E. Б., Больбух T. В., Семенов М. А. Изучение изотерм гидратацин нуклеиновых кислот.-Харьков, 1987.-19 с. (Препринт / АН УССР. ИРЭ, № 359).

2. Frechet $D$., Ehrlich R., Remy $P$. Thermal perturbation differential spectra of ribonucleic acids. 1. Hydration effects // Nucl. Acids Res. - 1979-7, N 7. - P. 1965-1980.

3. Thermal perturbation differential spectra of ribonucleic acids. 2. Nearest neighbour interactions / D. Frechet, R. Ehrlich, P. Remy, J. Gabarro-Arpa // Ibid.- P. 19812001 .

4. Маевский A. A. О температурной зависнмости электронных спектров поглошения полинуклеотидов и их компонентов // Бнофизика,-1975.-20, № 6.- С. 957-960.

5. Электронная структура, УФ-спектры поглощения и реакционная способность компонентов нуклеиновых кислот / А. В. Бородавкин, Э. И. Будовский, Ю. В. Морозов и др. // Итоги науки и техники.-М. : ВИНИТИ, 1977.-227 с. (Сер. Молекуляр. 6нопогия; Т. 14)

6. Сененов M. A., Малеев В. Я. Энергетика гидратации ДНК // Бнофизнка.- 1986.31 № 5 - C. $764-767$.

7. Нселедование гидратации компонентов нукленновых кислот методами ИК-спектроскопии и снерхвысокочастотной диэлектрометрни / M. А. Семенов, В. А. Кашпур, Т. В. Больбух, В. Я. Малеев // Биополимеры й клетка.-1987.-3, № 1.- С. 18-22.

8. Стариков $E$. Б., Семенов $M$. A. ИК-спектроскопическое и квантовомеханическое изучение гидратащии динатриевой соли цитидин-5'-монофосфата // Журн. физ. химин.-1988.-42, № 8.-C. $2120-2126$.

9. Калиния Ф. Л., Лобов В. П., Жидков В. А. Справочник по биохимии-Киев:Наук. думка, $1971 .-1013 \mathrm{c}$

10. Исследованис действия ионов двухвалентной меди на тепловую денатурацию ДНК / Ю. П. Благой, В. А. Сорокин, В. А. Валеев, Г. О. Гладченко // Молекуляр. био.л)гия. 1978.-12, ㅈo 4.- С. 795-805.

11. Тайдс У. Физические постоянные/Под ред. В. И. Рыдника.-М. : Госиздат физмат. лит., 1962.-40 с

12. Обнаружение слабых электронных взаимодействий при изучении переходов спираль - клубок в гомополинуклеотидах / В. А. Сорокин, И. В. Левченко, В. А. Ватеев, Ю. П. Б.тагой // Молекуляр. биология.-1988.-22, № 1.-С. $151-158$.

13. Мартин $P$. 5 . Мариам $R$. $X$ Взаимодействие между ионами металлов и нуклеиновыми основаниями, нуклеозидами и нуклеотидами в растворах// Ионы металлов в бнол. системах. Амбивалент. свойства нуклеотидов.- М. : Мир, 1982.- С. 53-103

14. Pullman B., Miertus S., Perahia L. Hydration scheme of the purine and pyrimidine bases and base-pairs of the nucleic acids // Theor. chim acta.-1979.-50. N 4.P. $317-2.25$

15. Зенгер $B$. Принципы структурной организации нуклеиновых кислот.- : : Мир, $1987,-584 \mathrm{c}$.

16. Химмеябблау Д. Прикладное нелинейное программирование.-М.:Мир, 1975.--534 c.

17. Dtutrozовая система оптимизации для ЕС ЭВМ/В. И. Белан. К. К. Маслов. А. А Моторная. В. И. Хатунцев // Пакеты прикл. программ. Програм. обеспечение оптимизац. задач.-M. : Наука, 1987.-C. 108-115.

18. Jaffe H. H., Orchin $M$. Theory and applications of ullraviolet spectroscopy. New Ynik: London: J. Willey and Sons, 1962.-P. 186-196.

19. Quantitative study of ordered water structure around a B-D $` A$ dodecamer / M. L. Kopka. A. V. Featini. N. Drew, R. E. Dickerson //J. Mol. Bio!-1983._163, N 1. P $129-146$

20. Spectroscopic studies of bivalent metal ion binding to single-stranded poly $\mathrm{C}$ / V. A. Sorokin, Yu. P. Blagoi, V. A. Vialeev et al.// Stud. bioplys.-1986.-114 $1-3$. P. $269-276$.

21. Arpalahti $J$. Lonnberg $H$. Complexing of 3 d-transition metal ions with 9 -substituted j)urines. 2. Sto:chiometry and thermodynamics of the complex formation//Inorg. clim. acta.-1983.-80, N 1.- P. 25-31.

22 Физико-химичсские свойства нуклеиновых кислот-М. Мир, $1976-314$ с.

23. Никососян Д. Н., Летохов В. С. Нелинейная лазерная фотофизика, фотохимия и фоrоб́⿴囗тогоя иуклеиновых кистот.- Троицк: Изд-во Тронцк. ин-та спектроскопии $1984-355$

24. Наһ̈рихин Ю. И. Проблема построения количественної молели строения воды // Журн. структир. хнмии.-1984.-25. № 2- - С. 60-67.

25. Букин B.A. Акустическое исследование гидратации нуклеиновых оснований в вод ных растворах. Анализ аномалий воды в гидратной оболочке // Бнофнзикі.-1988.-- 33, № 6.-.- C. 926-931.

Фнз.-тех. ин-т низких температур АН УССР, Харьков

Получено 03.02.89 


\title{
STUDIES IN HYDRATION ENERGETICS OF NUCLEIC ACID COMPONENTS BY THE DIFFERENTIAL UV-SPECTROSCOPIC METHOD
}

\author{
V. A. Sorokin, V. L. Galkin, V. A. Valeev, E. S. Arkhipova, \\ G. O. Gladchenko, Yu. P. Blagoi \\ Institute for Low Temperature Physics and Engineering, \\ Academy of Sciences of the Ukrainian SSR, Kharkov
}

$\mathrm{Sum} m$ ary

Differentiai UV spectra of CMP, UMP, AMP, IMP, GMP and Guo are obtained, which are due to dehydration of these substances during heating of their aqueous solutions from 20 to $90^{\circ} \mathrm{C}$. The enthalpies and entropies of hydration characterizing the interaction between water molecules and heteroatoms of the base rings are calculated. The entropy term yreatly contributed to the variations of the free Gibbs energy for UMP, IMP, AMP, GMP a:d Guo. The enthalpy and entropy terms are comparable for CMP.

удк 577.122 .3

Т. Ј. Јевитина, Н. М. Гусак, Н. В. Роднин, М. Т. Кириленко,

о. С. Мирошниченко, С. А. Атепалихина, Ј. В. Гудкова, Э. А. Козлов

\section{БРОМЦИАНОВЫЕ ФРАГМЕНТЫ RATAJAЗЫ ГРИЕA PENICILlIUM VITALE}

Каталазу $P$. vitale расщепляли бромцианом. Гель-фильтрованием через сефадексы, ионообменной хроматографией на различных ионообменниках, экстракцией бутанолом и водньм бифером, высоковольтным әлектрофорезом ка бумаге выделекы девять фрагментов, насчитывающих в сумме 387 аминокислотных остатков (50\% полипептидной цепи белка). Исследовали N-концевье аминокислотные последовательности, триптические и химотриптические пептиды этих фрагментов. В результате установлена полная "нинск:іслотная пос.едовательность фрагмента, включающего 61 остаток аминокислот, " частіиная аминокислотная последовательность деух фрагментов, насчитываницх $в$ су.и.не 37 остаткое.

Настоянее сообщсние является продолжением серии публикаций, посвященных исследованию первичной структуры каталазы $P$. vitale. llepзые трп работы $[1-3]$ освешают результаты изучения триптических пептидов.

Материалы и методы. Расщепление белка бромцианом осуществляли по методу Гроссз и Виткопа [4]. 800 мг ( 10 мкM) каталазы и 100 мг триптофана растворяли в $50 \mathrm{k.2} ; 0$; -ной НСООН. Добавляли бромциан (500 мг в 2 мл НСООН), выдержнвали $22:$ пюи комнатиой температуре в темноте и лиофилизнровали.

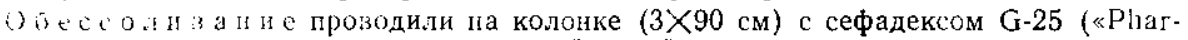
пасіа», Швеция), уравынепенным аммначной водой.

Ге егь-фильтров ан ие через сефадекс G-75 (грубый) («Pharmacia»). Растворители: а) 0,2 М трис-НCl-оуфер, $\mathrm{pH} 8,7$, содержащий $6 \mathrm{M} \mathrm{Gu} \cdot \mathrm{HCl}$; б) $20 \%$-ная НСООН. Полученные фракции обессоливали

Ио:ообмей ия хроматография. ДЭАЭ-сефадекс А-25 («Pharmacia»). Исходны: буфер: 0.05 $\mathrm{M}$ трис-НС!, pH 7.4. содержащнй $6 \mathrm{M}$ мочевину. Линейный градиент: 150 мл исходного буфера и 150 мл этого же буфера с добавкой $0,4 \mathrm{M} \mathrm{KCl}$. Сульфопропил (SP)-сефадекс C-50 («Plrarmacia»). Исходный буфер: универсальная буферная смесь, pH 3,7 [5], содержащая 6 M мочевину. Вогнутый градиент: 75 мл универсальнй буферной смеси, содержащей $6 \mathrm{M}$ мочевину, и 75 мл этой же смеси с добавкой $0,5 \mathrm{M} \mathrm{KCl.} \mathrm{Фракции,} \mathrm{полученные} \mathrm{ионообменной} \mathrm{хроматографией,} \mathrm{обессолива.ти.}$

Высокоэффективная жидкостная хроматография (ВЖKX). Прнменяли систему FPLC («Pharmacia»). Колонка моноQ. Исходный буфер: $0,02 \mathrm{M}$ трис$\mathrm{HCl}, \mathrm{pH} 7,4$. содержащ й $6 \mathrm{M}$ мочевину. Градиент создава.ли исходным буфером, содержащим $1 \mathrm{M}$ KС. Полученные фракции обессо:ива.ли.

экстракии ч бутано.том. Материал фракции растворя.ти в 50 мл $20 \%$-ной 